\title{
The Impacts of Co-creation of Local Culture English Books on EFL 5th Graders’ English Vocabulary Ability and Local Cultural Knowledge
}

\author{
Hsieh Yijung \\ Wen-aou Elementary School, Pinghu County, \\ Taiwan
}

\author{
Chen Chinfen \\ National Taipei University of Education, \\ Taipei, Taiwan
}

\begin{abstract}
The purpose of this study aims to explore the impacts of task-based co-creation of local picture books on facilitating the development of vocabulary ability and cultural knowledge of EFL 5th graders with different English proficiency levels in Taiwan. Twenty-one 5th graders participated in this study forty minutes per week, lasting for sixteen weeks. They were required to co-create English picture books of Pinghu through thematic task-based activities. Research data required for the study were collected through the pre-/post-tests of vocabulary and cultural knowledge, a participants' feedback questionnaire as well as semi-structured interviews. The results of this study showed that after experimental instruction, EFL 5th graders significantly improved their recognition of the connection between English word sounds and word meanings, word meanings and word forms, word forms and word meanings, as well as spellings. Moreover, their local cultural knowledge was improved significantly as well. Furthermore, based upon the 5th graders' responses to questionnaire and semi-structure interview, most of them developed a very positive attitude towards the activities of co-creating local picture books and their interest, self-confidence in English writing, and English learning behavior. Based on the findings, some suggestions were offered for the pedagogical applications and future studies.
\end{abstract}

Keywords: thematic writing, task-based co-creation of picture books, vocabulary ability, cultural knowledge, English learning attitude

\section{Introduction}

\section{Research Background and Motivation}

English education is now emerging in a rapid succession in Taiwan. Ministry of Education (MOE) announced that listening and speaking are the major two English abilities that the elementary school students have to develop before their graduation (MOE, 2008). However, the other two skills, reading and writing are not intentionally ignored. No matter what English language skills they might have, vocabulary plays a vital part in all of them (Laufer, 1998). In the Integrated Curriculum for 1st to 9th grades (IC1-9), MOE claims that the students from 3rd to 6th graders have to embrace the ability of spelling 180 basic common words at least and

Hsieh Yijung, Ed.M., Elementary School English Teacher, Wen-aou Elementary School.

Chen Chinfen, Ph.D., Professor \& Dean, Department and Graduate School of English Education, National Taipei University of Education. 
are able to freely use 300 words for daily usage. Based on that, vocabulary teaching and learning becomes the focus of Taiwan's elementary school English education.

In the past decades, many studies have proved that using children's literature as teaching materials could trigger learners' reading and writing abilities as well as foster their vocabulary development (Ghoson, 2002). Children's literature can widely range from picture storybooks, big books, predictable books, folktales, myths, science fiction, and biographies (Lynch-Brown \& Tomlinson, 2005). Among these literature genres, picture books are considered the best literary materials to promote EFL students' vocabulary learning and their culture knowledge (Chen, 2011; Du, 2013). Undoubtedly, language and culture are closely interrelated and, while learning the target language, learners would not only master the target language but also learn to appreciate the culture embedded in the target language. However, more than that, according to Integrated Grade 1-9 English Curriculum Standard, announced by the Ministry of Education, Taiwan, one of the objectives of English education at the primary and junior high school levels is to obtain the understanding of both local and foreign cultures. In other words, to learn a foreign language in Taiwanese context, EFL learners are supposed not only to master the linguistic knowledge and the cultural significance concealed in the target language but also to review and to compare their own language and culture with those in the foreign language, thereby exploring their own culture in depth and eventually being able to appreciate their own cultures fully and to share it with others in the target language.

Meanwhile, there have been a great deal of studies concerning the promotion of understanding cultural significance embedded in English picture books, but there are very few studies exploring the correlation between English picture books and EFL learners' knowledge of their own local culture.

In 2012, Penghu County or Pescadores Islands, an archipelago of 64 islands and islets in the Taiwan Strait, has been gazetted as the most spectacular and attentive natural restoration in Taiwan and ever slated for UNESCO's world heritage. Penghu County is boasted with many nature attractions such as Penghu National Scenic Area, Double-Heart of Stacked Stones, Little Taiwan and Whale Cave. Penghu County is admired for the grandeur and harmony of the natural landscapes of intermixed pillow basalts and dikes in 200-m thick, its more than 700 species of native and rarely-found oceanic and land animals and plants, precious coral reef biological system and endangered green turtles.

To appreciate Penghu's beauty and share it with the whole world, Penghu students are supposed to be able to know about their own culture thoroughly and introduce it to the people in the other countries in English. Since there are few chances for students in Penghu introducing our culture in English orally, the best way of presenting Penghu's beauty and culture is through the creation of English picture books. In the processes of co-creation the local picture books, the participating students are encouraged to co-author their own picture books, to illustrate the pictures describing their ideas and writings, to retrieve and organize their cultural knowledge, and to accomplish their writing cooperatively. Through the co-creation of local picture books, the participants might be beneficial to acquire English vocabulary words, one of the major objectives of EFL instruction, to embrace their own culture and to practice their reading and writing skills cooperatively. Concerning vocabulary learning, it has been defined as a kind of word recognition, the processes of identifying word orthography, pronunciation, and meaning (Perfetti, 1985). However, students participating in this study are EFL 5th graders, considered as EFL beginning learners with limited English knowledge. Thus, vocabulary learning in this study is specifically narrowed down to acquisition of the target words appearing in students' co-created local picture books in terms of word sounds, word forms, word meanings as well as word spellings. 
Furthermore, local cultural learning in this study is referred to the understanding of geographic features, plants and animals, and festivals in Penghu.

\section{Research Purposes and Research Questions}

Accordingly, this study aims to promote English vocabulary learning and local cultural knowledge of Penghu 5th graders, with different English proficiency levels, by means of implementing co-creation of local thematic English picture books (TCLPB). More specifically, three research questions are set up for this study to explore as follows:

Does TCLPB help improve English vocabulary ability of Penghu 5th graders, with different proficiency groups?

Does TCLPB help improve cultural knowledge of Penghu 5th graders, with different proficiency groups?

How do Penghu 5th graders with different English proficiency groups respond to TCLPB?

\section{Literature Review}

\section{Culture Learning}

Culture learning is best seen as a lived experience, as a personal encounter with another way of life whether it occurs in a foreign language or second language context (Moran, 2001). Culture learning is embedded in any language-learning environment, inside or outside the classroom, with or without teachers, through books or through people. Culture is the evolving way of life of a group of people, consisting of a shared set of practices, products, and perspectives within specific social contexts (Moran, 2001). Culture learning is recognized as a comparative process in which learners are encouraged to get aware of their own culture and contrast it with the target culture (Byram, 1997).

Penghu County has been approved as one of the most attractive bays around the world in 2012. Therefore, learning more about local culture is a must for Penghu students through formal school education and there is no exception for English classroom instruction. Hence, to have students to explore their own culture in English is set up as a major objective for this study.

Through years, from the 1960s to 2000s, discussions of the role of culture in language classroom have remained an important issue among scholars and language instructors in the language classroom (Karabinar, 2012). In culture-integrated classroom, the language instructors would assign curriculum that are intended to increase and strengthen learners' cultural knowledge and understandings.

To summarize it, cultural knowledge is the specific and general knowledge that students have to embrace. It is the ability that one stand back from our own viewpoint and is aware of cultural values, traditions and beliefs within our own and other culture. However, culture is a highly complicated and a broad concept and it is never easy to define in a simple terms. Therefore, in the study, the researcher is going to offer local topics, anticipating for increasing students' diverse cultural knowledge, to respect their own culture and foreign culture.

\section{Co-creation of Picture Books}

Picture books have been proved one of the most practical and valuable resources that language instructors can use in language learning (Slattery \& Willis, 2011). Picture books can foster children's imagination and even help them to create their own stories. With the pictures illustrated, children are inspired to write more sentences with more vocabulary words. When text is integrated with image, a symbiotic interaction occurs (Manifold, 2000). 
Picture books can be as the useful materials implemented in children's writing instruction. Writing opportunities should be practiced throughout the school days. The school curriculum should offer children opportunities to experience different types of text for various purposes and in multiple genres (Ovando, Combs, \& Collier, 2006). Meek (1996) stated that children could learn from any kinds of writing, which provide opportunities to refine use of various genre styles. Genre, according to Duke and Purcell-Gates (2003), refers to patterns in the manner in which language and illustrations are used to distinguish between different types of text, like information books and storybooks.

R. H. Yopp and H. K. Yopp (2000) defined information books typically present factual data or information using narrative or non-narrative language and including illustrations, photographs, and special language forms. Inan (2010) presented the features of information book as timeless verb constructions, generic noun constructions, repetitions of the topical theme, comparative and contrastive. On the other hand, storybooks include the elements of character, setting, problem, and solution. Harp and Brewer (2005) defined storybooks as offering a plot and including the elements of a setting, characters, and events that typically telling a tale in sequential order from beginning to end. In the study, each group has to follow these features to co-create their picture books in the genres of both storybook and information book.

\section{Cooperative Learning}

Socio-cultural and socio-historical theory informs language instructors that the process of learning language for students is relying so much on their learning community. Children are active members of a community and their language knowledge is constructed by the other community members (Wertsch, 1991). Cooperative learning promotes opportunities for interaction among students, which is essential to language learning (McCafferty, Jacobs, \& Iddings, 2006). Therefore, co-creating a picture book is considered as a robust practice for children. Creating a picture book as a group, children can share, interact and negotiate the information with their peers in a collaborative way.

If children are engaged in collaborative and inquiry activities, they would be led to a process of growth into the intellectual life (Vygotsky, 1978). Cooperative learning would therefore seem as a workable framework for addressing the needs of children because it promotes cooperation rather than competition.

Through providing opportunities for children to think and talk with their peers, it lessens their burden and anxiety in the process of writing story. In the current study, the researcher is going to provide the students the local topics such as animals, customs, and living styles as their target materials to co-write their picture books.

\section{Effects of Writing via Co-creating Picture Books}

Writing is the process of critical thinking. While involving writing, students are not only recalling thinking but also using the learned words and words they are going to learn. In order to communicate their ideas or thought successfully, students are trying to select the elaborate words to shorten their bridge between their readers. In other words, Writing is an interactive process between writer, text, and reader.

In the process of writing, writers equip the writing with vocabulary words to form ideas, recall experiences, and process sensory images that are stored in long-term memory (Flower \& Hayes, 1981). Therefore, vocabulary facilitates writing and writing builds up long-term used of vocabulary. In the current study, the researcher plays a supportive role in every step of writing and is responsible for assisting students to co-write the local picture books. Co-writing the local picture books can prompt what students learned surrounding their life and can be the tool of reviewing and retrieving vocabulary words. 


\section{Writing and Vocabulary Acquisition}

Vocabulary plays a vital part in the writing, and writing facilitates practicing vocabulary words. However, when students only copy or trace the vocabulary words without intending to convey its meaning through the meaningful output like composing a picture book, then vocabulary words are only the meaningless fragments (Barcroft, 2007). Writing is a form of output that can access the meaning of words. While students are composing the sentences, they are trying to retrieve learned words, integrating the target words required to describe in their picture books, then they are involving self-generation of writing. Once self-generation is triggered, vocabulary words are easy to memorize (Slamecka \& Graf, 1978).

Writing reinforces the development of vocabulary accumulated. In the process of co-writing, students are searching for specific and unique words that could represent their ideas and thought directly. Actually, vocabulary conveys content knowledge because specialized vocabulary are used to the certain context. When students use specialized vocabulary, they not only convey their understanding of a topic, they express their knowledge in a way that is valued and accepted by the discourse community for that field (Swales, 1988). Through the processes of co-writing the picture books, students can output the vocabulary contextualized and hence acquire its sound, form and meaning spontaneously.

\section{Writing and Culture Learning}

Many research found out that writing is one of the effective way for language learning, and cultural learning is no exception. Students could reflect on their cultural observations and real-world experiences through writing (Kim, 2008; Martin, 2009). Paper texts are beneficial for mapping learners' cultural and metacognitive awareness (Martin, 2009). While students are engaging in the creation of local picture books, they explore their own culture and record it with written form narratively. The students become members of their own cultures in terms of narrative. Culture needs a set of norms that can preserve it in terms of interpretive procedures and writing is one of an effective way to achieve it.

Writing through creation of the local picture books elicits students' sensitivity and identity of culture. While students are creating local picture books, the language instructor should remind students to consider the interplay between text and illustration that may represent historical elements, cultural details, and regional authenticity (Mahurt, 2005). Based on the authentic materials provided by the researcher in the present study, students are going to co-write a local book with their drawings to describe what they are going to convey.

\section{Summary}

From the literature reviewed above, several observations are found. First, integrating local culture themes into foreign language curriculum are beneficial for students' understanding of their own culture and respect for the foreign cultures, which is one of the most important functions of language education. Second, task-based co-creation of local picture books (TCLPB) can be an effective teaching mode to practice in the language classroom. In TCLPB, students are encouraged to use the target language to communicate with each other under the local themes. Therefore, students are seen as a language user not as a language learner. In other words, TCLPB links the word meaning and its form that students are supposed to acquire through the meaningful tasks with the target language. Third, writing is playing a significant role in enhancing students' vocabulary and cultural knowledge. In the processes of writing, students are invited to apply English words to their picture books; hence, facilitating the acquisition of vocabulary spontaneously. Besides, writing the local picture books requires students' understanding about their own culture, and therefore, promotes their cultural knowledge. 
Based on these conclusions, the study is going to investigate the impacts of TCLPB on Penghu 5th graders' English vocabulary learning and cultural knowledge. Methodology is going to be presented in the following chapter.

\section{Methodology}

This study was a single-group design because of the limited number of students at school. The independent variable of the study is the implementation of co-creation of local picture books and the dependent variables are the progress of 5th graders' English vocabulary ability, their understanding of their local culture, including animals (green sea turtle), customs (fireworks festival), and living styles (stone weirs), and their attitude toward TCLPB.

Data were collected qualitatively and quantitatively through English vocabulary tests and cultural knowledge tests, which were implemented to evaluate students' progress of their vocabulary ability and their understanding about the local culture, and a feedback questionnaire, which was used to understand students' English learning experiences and their feedback towards TCLPB. The study lasted for a whole school year, from October 2013 to December of 2014, including the preparation stage, implementation of experimental instruction to the post experimental stage of data analysis and thesis writing.

\section{Research Setting and Students}

The study was conducted in a public elementary school in Penghu County, where students started their English classes from the first grade, two classes per week. In addition to the regular classrooms, there are some English thematic learning classrooms decorated with local culture, local food, local living styles, and local ecology. English education is emphasized and well supported by the school administrators and local communities.

Twenty-one 5th graders in a public elementary school in Penghu County participated in this study, including nine boys and twelve girls. They were divided into four groups with five to six students heterogeneously. Their average age was 11 years old. Those students have had similar family background and English learning experiences. Ninety-five percent of their parents are very positive toward English education but offer little help to their children's learning due to personal limited English literacy. Few of them received after-school English learning nor did they study at home with companions. Most of the students have poor English vocabulary ability and trouble in English reading and writing.

Based on the distribution density of vocabulary pretest, students in this study were grouped as high, intermediate, and low achievers. The high achievers (H6, H7, H15, H16, H18, H19, H21) are those whose scores over 70, and those whose scores between 51 to 69 are intermediate achievers (I1, I4, I11, I13), and the low achievers (L2, L3, L5, L8, L9, L10, L12, L14, L17, L20) are those whose scores below 50 on the pretest.

\section{Experimental Instruction}

This experimental instruction of this study was conducted in the English classroom, 40 minutes a week, lasting for 16 weeks. The teaching and learning materials adopted in the study were derived from local resources, which could be accessed from the websites of Penghu County Government, Penghu Tourism Department, and Penghu Cultural Affairs Bureau, and certain local websites provided by the instructor. Themes for students to explore were pre-assigned based on their interesting themes from their background questionnaire, 
including green sea turtles, fireworks festival, and stone weirs representing local features. The three themes were the targets for students to discover and to put what they found into their picture books.

The first two weeks were the time to deliver Background Questionnaire, English Vocabulary Pre-test, and Cultural Knowledge Pre-test to collect students' background information of English learning experiences, initial English proficiency and initial knowledge of local cultures. Then, every thematic instruction was conducted for three weeks respectively. The posttests of English Vocabulary and Cultural Knowledge, to evaluate students' learning results, were conducted in the last two weeks.

The procedure of every task-based thematic instruction was based upon Willis' three phases of Task-Based Learning Framework (1996), including Pre-task, where the instructor explains the objectives and content of the tasks and demonstrate how to process the tasks, Task Cycle, where students start to conduct their tasks, surveying data, planning and implementing their tasks and finally reporting their tasks with other groups, and Post-task, where the instructor reviews and analyzes key words and sentence patterns applied in the tasks (language focus), and offers diverse learning activities for students to master those key words.

The details of teaching procedure of each task-based thematic instruction task are shown in Table 1.

Table 1

Example of Teaching Procedure of Task-based Thematic Instruction

\begin{tabular}{ll}
\hline Week & Content of activities \\
\hline 1 & $\begin{array}{l}\text { Pre-task: Explanation and demonstration ( } 40 \text { minutes) } \\
\text { The instructor introduced and instructed the genres of picture books and further explained the details of tasks, including } \\
\text { the rules of group discussions, and finally assigned each group a writing genre with } 17 \text { must-use vocabulary of green } \\
\text { sea turtle taught. } \\
\text { Task cycle: Task, planning and report ( } 80 \text { minutes) } \\
\text { Each group surfed online about green sea turtles, planed the content of their storybooks, co-wrote and drew the book, } \\
\text { and shared it with the whole class with PPTs at the end of this cycle. } \\
\text { Post-task: Language focus, analysis and practice ( } 40 \text { minutes) } \\
\text { The instructor gave comments on their works respectively and then reviewed } 17 \text { must-be vocabulary with PPTs and by } \\
\text { applying games. }\end{array}$ \\
\end{tabular}

\section{Instruments}

The instruments adopted to collect data for this study included students' background questionnaire, English vocabulary tests (a pre/posttest of English vocabulary), pre/posttest of cultural knowledge, students' feedback questionnaire, and semi-structured interviews.

Students' background questionnaire. At the beginning of the study, students' background questionnaire was delivered to students to understand their experiences of learning English and reading English picture books, their views and motivation on English learning and their parents' attitude toward English education.

English vocabulary test. The pre/posttests English vocabulary were self-designed based upon the content of picture books and were conducted at the beginning and the end of the study. It was intended to evaluate the impacts of implementing the experimental instruction on the promotion of students' English vocabulary ability. The content of the pre- and the post- English vocabulary tests are the same but arranged in different order. To balance each test section, the researcher delivered 50 English words into four types of testing items (see Table 2). 
Table 2

The Vocabulary in Each Testing Section

\begin{tabular}{lllll}
\hline \multirow{2}{*}{ Themes } & Part A & Part B & Part C & Part D \\
\cline { 2 - 4 } & $\begin{array}{l}\text { Listen and choose } \\
\text { (sound-meaning) }\end{array}$ & $\begin{array}{l}\text { Read and choose } \\
\text { (picture-form) }\end{array}$ & $\begin{array}{l}\text { Read and write } \\
\text { (form-meaning) }\end{array}$ & Read and write (spelling) \\
\hline $\begin{array}{l}\text { Green sea turtle } \\
\text { (17 words) }\end{array}$ & $\begin{array}{l}\text { dig/hungry/shark } \\
\text { /animals/beach/ }\end{array}$ & $\begin{array}{l}\text { sea weed/ } \\
\text { ocean/nest/lay }\end{array}$ & $\begin{array}{l}\text { jellyfish/ } \\
\text { Wang-an/ } \\
\text { protected/ } \\
\text { people } \\
\text { hold/excited/ } \\
\text { take photos /attract } \\
\text { famous/build/ } \\
\text { fishermen/ } \\
\text { /Chi-mei }\end{array}$ & green/eat \\
$\begin{array}{l}\text { Fireworks festival } \\
\text { Stone weirs }\end{array}$ & $\begin{array}{l}\text { fireworks/ } \\
\text { (15 words) }\end{array}$ & summer/heart & $\begin{array}{l}\text { tourist/show/ } \\
\text { rainbow/ bridge } \\
\text { twin/net/stone/ } \\
\text { strong }\end{array}$ & $\begin{array}{l}\text { April/June/ } \\
\text { color/blue/visit/star/shape } \\
\text { water/wind/ } \\
\text { catch/use /sea }\end{array}$ \\
\hline
\end{tabular}

Total: 50 words

The total words examined in the English vocabulary test are 50, 17 of which are derived from the theme of green sea turtles, 18 from the theme of fireworks festival, and 15 from the theme of stone weirs. These 50 words were required to be integrated into students' storybooks.

The English vocabulary test contained four kinds of test genres in the form of multiple-choice questions, mainly examining the correspondence of word sounds and word meanings, the correspondence of word meanings and word forms, the matching of English and Chinese meanings, and the correct spell of those words. It contains 50 items, each for two points and totaling 100 points.

Cultural knowledge tests. The pre/posttest cultural knowledge, conducted at the beginning and at the end of the study aimed to examine students' understanding of the target themes, green sea turtles, fireworks festival and stone weirs, the representative features of Penghu County. The content of both tests is the same but arranged in different order. The test contains 25 items with true and false questions, each for four points and totaling 100 points.

Students' feedback questionnaire. The feedback questionnaire administrated at the end of the study is to understand students' feedback on vocabulary learning and cultural knowledge through TCLPB. This questionnaire was composed of 20 questions in Liker's 4-point scale, surveying three aspects of students' feedbacks: (1) students' confidence and interest in English learning; (2) students' learning behavior; and (3) students' knowledge and attitude towards TCLPB.

Semi-structured interviews. Semi-structured interviews were conducted to further examine the influential factors that might affect both high and low achievers' preferences in participating in the activities of TCLPB. A total of 21 students, seven from high, intermediate and low English proficiency groups respective, were interviewed. The content of interviews include students' favorite genres of writing, their favorite themes, the most impressive events occurring during the creation of picture books, and the most difficulties they were encountered during TCLPB.

\section{Data Analysis}

Data collected from each instrument were documented and analyzed by using Statistical Package for the Social Science (SPSS). The students' scores in the pre/posttests were analyzed by paired sample $t$-test to examine whether the activity of TCLPB has significant impacts on students' learning results in English vocabulary and local cultural knowledge. The feedback questionnaire of students was analyzed descriptively in 
terms of means and percentages of respondent on each item.

The semi-structured interviews were conducted in Chinese, and interview data were transcribed and translated into English and then further analyzed descriptively in percentages of respondent on each item as well as in triangulated with the researcher's observation.

\section{Results and Discussions}

Data collected through diverse instruments were organized, analyzed, and interpreted from four aspects: (1) impacts of TCLPB on the improvement of students' vocabulary ability; (2) impacts of TCLPB on the increase of students' local cultural knowledge; (3) students' feedback toward on the task of co-creating English picture books; and (4) results of semi-structured interviews.

\section{Impacts of TCLPB on the Improvement of Students' Vocabulary Ability}

In order to measure the impacts of TCLPB on students' vocabulary ability, the pre- and post-tests of English vocabulary were given before and after the experimental instruction. The statistical analysis of the overall performance of vocabulary tests was examined first, and then was that of individual aspect of vocabulary ability. The mean score of test is computed and compared by employing paired samples $t$-test to find out if there are significant differences between students' performance in the pre- and posttests of vocabulary knowledge within the group. The performance of high, intermediate and low achievers is also compared and discussed respectively to find out if the impacts of TCLPB on students with different English proficiency levels are significantly different.

Comparison of students' performance in pre- and post- vocabulary tests. Students' overall performance on the English vocabulary pretest and posttest is compared to evaluate their progress in vocabulary ability after receiving the experimental instruction. The results are shown in Table 3.

Table 3

Comparison of Students' Performance in Pre- and Post- Vocabulary Tests

\begin{tabular}{|c|c|c|c|c|c|c|}
\hline Aspect & Test & Mean & $\%$ of correction & SD & $\begin{array}{l}\text { Increase } \\
(\%)\end{array}$ & $\mathrm{t}$ \\
\hline \multirow{2}{*}{$\begin{array}{l}\text { S-M } \\
(20 \%)\end{array}$} & Pre- & 14.29 & $71.45 \%$ & 3.42 & \multirow{2}{*}{$\begin{array}{l}5.42 \\
(37.93 \%)\end{array}$} & \multirow{2}{*}{$7.55^{* * *}$} \\
\hline & Post- & 19.71 & $98.55 \%$ & 0.96 & & \\
\hline \multirow{2}{*}{$\begin{array}{l}\text { P-F } \\
(24 \%) \\
\end{array}$} & Pre- & 13.71 & $57.13 \%$ & 5.07 & \multirow{2}{*}{$\begin{array}{l}7.81 \\
(56.96 \%)\end{array}$} & \multirow{2}{*}{$8.01 * * *$} \\
\hline & Post- & 21.52 & $89.67 \%$ & 4.85 & & \\
\hline \multirow{2}{*}{$\begin{array}{l}\text { F-M } \\
(28 \%)\end{array}$} & Pre- & 8.00 & $28.57 \%$ & 6.78 & \multirow{2}{*}{$\begin{array}{l}14.29 \\
(178.6 \%)\end{array}$} & \multirow{2}{*}{$10.55^{* * *}$} \\
\hline & Post- & 22.29 & $79.61 \%$ & 8.40 & & \\
\hline \multirow{2}{*}{$\begin{array}{l}\text { Spelling } \\
(28 \%)\end{array}$} & Pre- & 12.76 & $45.57 \%$ & 9.46 & \multirow{2}{*}{$\begin{array}{l}8.95 \\
(70.14 \%)\end{array}$} & \multirow{2}{*}{$6.56^{* * *}$} \\
\hline & Post- & 21.71 & $77.54 \%$ & 9.62 & & \\
\hline \multirow{2}{*}{$\begin{array}{l}\text { Total } \\
(100 \%)\end{array}$} & Pre- & 49.81 & $49.81 \%$ & 22.13 & \multirow{2}{*}{$\begin{array}{l}35.05 \\
(70.37 \%)\end{array}$} & \multirow{2}{*}{$10.29 * * *$} \\
\hline & Post- & 84.86 & $84.86 \%$ & 24.17 & & \\
\hline
\end{tabular}

Notes. ${ }^{* * *} p<.001 . \mathrm{S}-\mathrm{M}=$ correspondence between sound and meaning; $\mathrm{P}-\mathrm{M}=$ matching of picture to meaning; $\mathrm{F}-\mathrm{M}=$ correspondence between form and meaning.

The results showed that mean score of overall vocabulary tests increased from 49.81 in the pretest to 84.86 in the posttest by 35.05 (improving response accuracy by 70.37\%) in general, which reaches the significant level $\left(t=-10.29, p<.000^{* * *}\right)$. Generally speaking, students in this study made significant progress after experiencing TCLPB. 
Furthermore, students' performance in the individual aspect in the pre- and posttests were also analyzed. In the aspect of the recognition of word sounds to word meanings, the mean (percentage of correction) that students gained was from $14.29(71.45 \%)$ in the pretest to 19.71 (98.55\%) in the posttest, increasing 5.42 (37.93\%), reaching significant level $\left(t=-7.55, p=.000^{* * *}\right)$. In the aspect of matching pictures to word forms, the mean was from 13.71 (57.13\%) to 21.52 (89.67\%), increasing 7.81 (56.96\%), which also reaches significant level ( $\left.t=-8.01, p=.000^{* * *}\right)$. In the aspect of the correspondence between word forms and word meanings, the mean students gained was from 8.00 (28.57\%) to 22.29 (79.61\%), increasing 14.29 (178.6\%), reaching significant level $\left(t=-10.55, p=.000^{* * *}\right)$. In the aspect of spelling, the most difficult part in students' English learning experience, the mean that students gained was from 12.76 (45.57\%) to 21.71 (77.54\%), increasing 8.95 (70.14\%), reaching significant level ( $t=-6.56, p=.000 * * *)$ as well.

In sum, after experiencing TCLPB, most students in the study might recognize the connection between word sounds and word meanings, match pictures and word forms, examine the correspondence between word forms and word meanings and spell those key words correctly. It implies that TCLPB might enhance students' English vocabulary ability significantly. The reasons for the significant improvement might be because of the task topics adopted in this study appealing to students' interest and closely related to students' daily life experience (Tang, 2012; Ni, 2014). It might also be because the pictures illustrated, which highly inspired students to write with more sentences and more words (Tsai, 2013). The result of the study fully echoes Slattery and Willis' suggestion that picture books are one of the most practical and valuable resources that language instructors can use in their language learning (2011).

Furthermore, to find out which group of students might benefit most from the learning activity of TCLPB, the performance of students with different English proficiency levels were examined. The statistical analysis of high, intermediate, and low achievers' overall performance on the pre- and post- vocabulary tests were shown in Table 4.

Table 4

High, Intermediate, and Low Achievers' Overall Performance on Vocabulary Tests

\begin{tabular}{lllllll}
\hline Group & $\mathrm{N}$ & Test & Mean & $S D$ & Progress (\%) & $t$ \\
\hline \multirow{2}{*}{ High } & 7 & Pre- & 74.00 & 4.0 & +25.43 & \multirow{2}{*}{$18.69^{* * *}$} \\
\hline \multirow{2}{*}{ Intermediate } & 7 & Post- & 99.43 & 1.5 & $(34.36 \%)$ & \multirow{2}{*}{$15.51^{* * *}$} \\
\hline \multirow{2}{*}{ Low } & 4 & Pre- & 59 & 6 & +38.00 & $(64.41 \%)$ \\
\hline
\end{tabular}

Note. ${ }^{* * *} p<.001$.

As the results shown in Table 4, there was a great rise in mean scores of three groups of students. The high achievers improved 25.43 (increasing response accuracy by 34.36\%), the intermediate achievers improved 38 (64.41\%), and the low achievers gained 40.4 (137.41\%), all of which improved significantly $(t=-18.69, p$ $<.001 ; t=-15.51, p<.001 ; t=-6.23, p<.001)$. Based upon the percentage of progress, the mean scores that the high and intermediate achievers gained are almost full, 99.43 and 97 respectively; meanwhile low achievers benefited most from TCLPB, which is quite surprising and encouraging to instructors who have been searching for effective learning activities to promote low achievers' performance.

Actually, the finding is different from that in Hsieh's study (2013) that the task-based learning activities 
are more appropriate for the students with high and intermediate English proficiency than for those with low English proficiency. The reason causing the different study results probably are because of the different content of the tasks conducted in the two studies. In Hsieh's study, students were required to complete an open-question task, which requires better vocabulary competence so that it is a relatively hard for students with low English proficiency to complete. While, in this study, the tasks are closely related to students' daily life experiences and the words and sentences applied by students are so familiar and concrete that low achievers were highly motivated to learn and to practice. Accordingly, students with low English proficiency still could complete the tasks, which gave them the sense of achievement and maintaining their interest and confidence on what they were learning.

Generally speaking, task-based language learning emphasizes the process of meaning conveying, including a focus on form. The marriage of meaning and form is one of the key features of TBLT (Long \& Norris, 2000), through which students in this study improved a lot in recognizing word words, word forms and word meanings. Furthermore, it enhances students' spelling ability, the most challenging aspect for EFL students to master, which echoes Ni's finding (2012) that task-based activities are beneficial for EFL students to promote their English vocabulary proficiency, especially in the aspect of spelling. Above all, intensive writing practice among peers is another key factor of improving students' word recognition ability. As Barcroft (2007) claimed that writing is a form of output that can access the meaning of words. While composing sentences, students are trying to retrieve learned words, integrating the target words required to describe in their picture books. Once self-generation is triggered, vocabulary words are easy to memorize (Slamecka \& Graf, 1978). To sum up, after TCLPB, students of all three proficiency levels made significant improvement in English vocabulary ability in the recognition of word sounds, word forms, and word meanings as well as in word spelling.

\section{Impacts of Co-creation of English Picture Books on Students’ Local Cultural Knowledge}

To examine how TCLPB activities influenced students with different proficiency levels on their cultural knowledge, the mean score of test was computed and compared by employing paired samples $t$-test and further discussed respectively to find out if the impacts of TCLPB on students with different English proficiency levels are significantly different. Table 5 lists 21 students' performance on the pretest and the posttest of their cultural knowledge.

Table 5

Students' Performance on the Pretest and Posttest of Cultural Knowledge

\begin{tabular}{|c|c|c|c|c|c|c|}
\hline Group & $N$ & Test & Mean & $S D$ & Progress & $t$ \\
\hline \multirow{2}{*}{ All } & 21 & Pre- & 75.24 & 9.01 & \multirow{2}{*}{$\begin{array}{l}+12.62 \\
(16.77 \%)\end{array}$} & \multirow{2}{*}{$6.84 * * *$} \\
\hline & 21 & Post- & 87.86 & 8.45 & & \\
\hline \multirow{2}{*}{ High } & 7 & Pre- & 77.14 & 8.59 & \multirow{2}{*}{$\begin{array}{l}+14.29 \\
(18.52 \%)\end{array}$} & \multirow{2}{*}{$20.00 * * *$} \\
\hline & 7 & Post- & 91.43 & 9.45 & & \\
\hline \multirow{2}{*}{ Intermediate } & 4 & Pre- & 71.25 & 11.09 & \multirow{2}{*}{$\begin{array}{l}+16.25 \\
(22.81 \%)\end{array}$} & \multirow{2}{*}{$3.153^{*}$} \\
\hline & 4 & Post- & 87.50 & 8.66 & & \\
\hline \multirow{2}{*}{ Low } & 10 & Pre- & 75.50 & 8.96 & \multirow{2}{*}{$\begin{array}{l}+10 \\
(13.25 \%)\end{array}$} & \multirow{2}{*}{$3.078^{*}$} \\
\hline & 10 & Post- & 85.50 & 7.62 & & \\
\hline
\end{tabular}

Notes. ${ }^{*} p<.05 ; * * * p<.001$. Total scores $=100$.

As the results shown in Table 5, there was a significant rise of local cultural knowledge among high, 
intermediate, and low achievers in the study and the intermediate group progressed most. In fact, before the study, three groups of students performed similar to each other, with average mean score 75.24 points. After TCLPB activities, the high achievers gained 91.43 points, the intermediate achievers 87.50 points and the low achievers 85.50 points, and their improvement rates are $18.52 \%, 22.81 \%$, and $13.25 \%$ respectively, all of which reached significant level $(t=-20.00, p=.000 ; t=-3.153, p=.050 ; t=-3.078, p=.013)$. The study results indicate that all of the students with three different proficiency levels made significant progress in the posttest of their cultural knowledge. The positive results of TCLPB might suggest that TCLPB is an effective teaching strategy to help students develop local cultural knowledge and to be implemented in the language classroom to increase and to retain their understanding of local culture. It is because while students are engaging in the creation of local picture books under the themes of local topics, green sea turtles, fireworks festival, and stone weirs, which are interesting, familiar and related to their real life, they explore those themes and record them in written form narratively. The result of the study confirms Martin's suggestion (2009) that paper texts are beneficial for mapping learners' cultural and metacognitive awareness. In other words, as Marlowe and Page's claim (2005), through the processes of TCLPB, students discovered their own culture and their cultural understanding and knowledge became deeper, more comprehensive, and longer lasting.

\section{Students' Co-creation Works}

During this study, students were divided into four groups and supposed to create books with three topics (green sea turtles, fireworks festival, and stone weirs,) written in two genres (information book and story books). In other words, each group created two different genres of picture books.

Group 1 and Group 2 were assigned to write on the topic "green sea turtles" in the genre of information book, and "fireworks festival" in the genre of storybook. Meanwhile, Group 3 and Group 4 were assigned to write on the topic "green sea turtles" in the genre of story book, and "fireworks festival" in the genre of information book storybook. At the last topic of "stone weirs", all of the four groups made their own decision of what kind of book they would like to create.

It was regulated that every picture book must include one to three sentences in one page, totally five pages. A list of the target words which were required to be integrated into each of their creations was offered in advance. After each group's first draft, the researcher corrected their grammars, and each group had to revise their grammars before presenting their picture books.

As to the content of the picture books in the genre of information books, students were required to take references of the materials they searched online or in texts and presented those information or factual data in narrative or non-narrative language with repetition of topical theme and illustrations. The target words used in the picture books should be underlined (See Appendix A).

As to the content of the picture book in the genre of storybooks, several key elements must be included, such as plots, characters, settings, problems, and solutions and present their story in a logical way. The target words which are required to be included should be underlined (See Appendix B).

No matter what genre of picture books they created, each group must integrate the target vocabulary into their picture books effectively and drew pictures in accordance with the sentences they made. In the creation of information books, the students offered the factual events and the most valuable information for the readers. In the creation of storybooks, they created attractive characters, and appealing plots for readers. With the pictures illustrated, children are inspired to write more sentences with more vocabulary words. When text is integrated 
with image, a symbiotic interaction occurs (Manifold, 2000). Students' picture-book creation in this study indeed proved that creation of picture books is one of the most practical and valuable learning strategy that language instructors can use in language learning.

\section{Students' Feedback on Co-creation of English Picture Books}

The students' feedback towards TCLPB was surveyed with a feedback questionnaire in 4-point Likert Scale, which is designed to investigate three aspects of students' feedback: students' confidence and interests in taking TCLPB, their reaction of learning behaviors, and their reaction of learning local cultural through TCLPB. The options in the questionnaire are "strongly agree (SA)", "agree (A)", "disagree (DA)", and "strongly disagree (SD)", scoring 4 points, 3 points, two points and one point respectively. The percentage of students' responses (number of students choosing the option/ the total number of students) in each option is also calculated and presented as the following.

Students' confidence and interests in receiving TCLPB instruction. Q1 to Q10 in the questionnaire is to investigate students' confidence and interest in taking TCLPB and the number of students and their responses for options (in percentage) are show in Table 6.

Table 6

Students' Confidence and Interest in Receiving TCLPB Instruction $(N=21)$

\begin{tabular}{|c|c|c|c|c|c|}
\hline No & Questions & SA (\%) & $\mathrm{A}(\%)$ & $\mathrm{D}(\%)$ & SD (\%) \\
\hline \multirow{2}{*}{1} & \multirow{2}{*}{ TCLPB enhanced my English ability. } & 11 & 10 & 0 & 0 \\
\hline & & $52.38 \%$ & $47.62 \%$ & $0 \%$ & $0 \%$ \\
\hline \multirow{2}{*}{2} & \multirow{2}{*}{ TCLPB increased my English vocabulary. } & 12 & 9 & 0 & 0 \\
\hline & & $57.14 \%$ & 42.86 & $0 \%$ & $0 \%$ \\
\hline \multirow{2}{*}{3} & \multirow{2}{*}{ The activity of TCLPB was too complicated. } & 1 & 7 & 5 & 8 \\
\hline & & $4.76 \%$ & $33.33 \%$ & $23.81 \%$ & $38.10 \%$ \\
\hline \multirow{2}{*}{4} & \multirow{2}{*}{ I would like to use TCLPB to learn English. } & 11 & 5 & 5 & 0 \\
\hline & & $52.38 \%$ & $23.81 \%$ & $23.81 \%$ & $0 \%$ \\
\hline \multirow{2}{*}{5} & \multirow{2}{*}{ TCLPB was an unappealing activity. } & 1 & 1 & 10 & 9 \\
\hline & & $4.76 \%$ & $4.76 \%$ & $47.62 \%$ & $42.86 \%$ \\
\hline \multirow{2}{*}{6} & \multirow{2}{*}{ I don’t like to listen to other groups’ picture books. } & 0 & 0 & 10 & 11 \\
\hline & & $0 \%$ & $0 \%$ & $47.62 \%$ & $52.38 \%$ \\
\hline \multirow{2}{*}{7} & \multirow{2}{*}{ I liked to co-create local picture books with my classmates. } & 9 & 8 & 4 & 1 \\
\hline & & $42.86 \%$ & $38.10 \%$ & $19.05 \%$ & $4.76 \%$ \\
\hline \multirow{2}{*}{8} & \multirow{2}{*}{ I hope I can keep the activity of TCLPB next semester. } & 12 & 3 & 4 & 2 \\
\hline & & $57.14 \%$ & $14.29 \%$ & $19.05 \%$ & $9.52 \%$ \\
\hline \multirow{2}{*}{9} & \multirow{2}{*}{ I could apply daily-life events to the co-creation of picture books. } & 8 & 8 & 3 & 2 \\
\hline & & $38.10 \%$ & $38.10 \%$ & $14.29 \%$ & $9.52 \%$ \\
\hline \multirow[t]{2}{*}{10} & \multirow[t]{2}{*}{ I could talk about the local materials in English through the activity of TCLPB. } & 6 & 9 & 5 & 1 \\
\hline & & $28.57 \%$ & $42.86 \%$ & $23.81 \%$ & $4.76 \%$ \\
\hline
\end{tabular}

Based upon the data presented in Table 6, almost all the students agreed and strongly agreed that TCLPB could enhance their English ability and help them increase their vocabulary words. Furthermore, 76.19\% students thought that they would like to learning English though TCLPB, and like to co-create local picture books with their classmates (80.96\%), and hoped they could keep the activity of TCLPB next semester (71.43\%). Furthermore, more than $70 \%$ of them thought they were able to talk about their local culture in English and apply daily-life events to their picture books after the study. Their responses above show that they became more confident in their own English ability and they did recognize the positive impacts on TCLPB in their English learning.

Furthermore, approximate 90\% of the students agreed that TCLPB was an appealing activity, and $100 \%$ of 
the students liked to listen to other groups' picture books during the sharing time and approximate $60 \%$ of the students thought TCLPB was not a complicated activity. According to the researcher's observation, peer cooperation during the process of creating picture books might be one of the key factors enhancing students' confidence and interest in TCLPB activities. As Tsai's statement (2013), co-writing picture books could trigger students' motivation to discuss in a collaborative way, thus promoting their confidence and interest in writing.

However, there were still 38.09\% students from 3 groups (L3, L5, L9, L20; I1, I11; H7, H15) felt that TCLPB was too complicated for them to work on. The main reason for the negative response of those students might be that students were required to use the specific words into their elaborative writing, which might block their fluency of writing. These specific words were completely new to them, and no sufficient opportunities offered for them to practice these words in different contexts. This result corroborated Barcroft's (2007) finding that the tasks that require learners to elaborate on word meaning at the initial stage of writing can detract their ability to learn new word forms.

Students' learning behavior during TCLPB activities. The aspect of how students behaved during TCLPB was also investigated through Q11 to Q15, and students' responses toward these five questions are show as follows (see Table 7).

Table 7

Students' Learning Behavior During TCLPB $(N=21)$

\begin{tabular}{|c|c|c|c|c|c|}
\hline No & Questions & SA (\%) & A (\%) & $\mathrm{D}(\%)$ & SD (\%) \\
\hline \multirow{2}{*}{11} & \multirow{2}{*}{ I cooperated with my teammates in creating story books during TCLPB. } & 10 & 8 & 1 & 1 \\
\hline & & $47.62 \%$ & $38.10 \%$ & $4.76 \%$ & $4.76 \%$ \\
\hline \multirow{2}{*}{12} & \multirow{2}{*}{ I seldom talked in the co-creation of picture books. } & 3 & 3 & 8 & 7 \\
\hline & & $14.29 \%$ & $14.29 \%$ & $38.10 \%$ & $33.33 \%$ \\
\hline \multirow{2}{*}{13} & \multirow{2}{*}{ I was involved a lot in the co-creation of picture books. } & 7 & 10 & 3 & 1 \\
\hline & & $33.33 \%$ & $47.62 \%$ & $14.29 \%$ & $4.76 \%$ \\
\hline \multirow{2}{*}{14} & \multirow{2}{*}{ I often had conflicts with my teammates. } & 2 & 7 & 8 & 4 \\
\hline & & $9.52 \%$ & $33.33 \%$ & $38.10 \%$ & $19.05 \%$ \\
\hline \multirow{2}{*}{15} & \multirow{2}{*}{ I reviewed and used the learned words in our picture books. } & 10 & 9 & 2 & 0 \\
\hline & & $47.62 \%$ & $42.86 \%$ & $9.52 \%$ & $0 \%$ \\
\hline
\end{tabular}

Based upon students' answers to Q11 to Q15, most of the students, except two students, agreed that they cooperated with my teammates in creating story books during TCLPB and more than $80 \%$ of them were involved a lot in the co-creation of picture books. Furthermore, $90.48 \%$ of students reviewed the words they learned before in the co-creation of picture books, which implies that during the creation of story books, students retrieved learned words and embedded those words into their picture books. As Swales' claim, when writers use specialized vocabulary, they not only convey their understanding of a topic, but also express their knowledge in a way that is valued and accepted by the discourse community for that field (1988).

As to approximate $30 \%$ of students confessed that they seldom talked in the co-creation of picture books, it is really a challenge that often occurs in a collaborative learning setting because of the diverse English proficiency levels among students. The students with high proficiency are usually dominating the whole process of the cooperative work and those with low proficiency keep silent or act indifferently or passively in the cooperative work. In the current study, the students were grouping heterogeneously. Each individual acted a different role during the co-creation of picture books. For the sake of different personalities, some students talked actively while some talked less in their group. Based on the researcher's classroom observation, those students who talked less during the co-creation of picture books are those who are shy and lack confidence in 
English learning. They are afraid of making mistakes among peers; therefore, they avoid talking actively during the co-creation of picture books. Individuals prefer to say nothing than to be disapproved and be rejected by others (Saunders \& Chester, 2008). On the other hands, approximate $42.85 \%$ of students said that they had conflicts with their teammates. Actually, it is inevitable during the process of cooperative learning activities. It is because students were assigned heterogeneously in the study, and they were supposed to learn how to convey their own ideas and convinced others through interactive discussions and negotiations with their team members to reach a consensus. The study phenomenon echoes Kessler's theory (1992) that cooperative learning offers more opportunity for language development and for integrating language with content through increased active communication, increased complexity of communication, and use of language for academic and social functions.

Students' reaction toward learning local culture via TCLPB. The last aspect investigated through Q16 to Q20 of the questionnaire is students' reaction toward learning local cultural knowledge through TCLPB. The percentage scores of the students' reaction to Q16 to Q20 are show in Table 8.

Table 8

Students' Reaction Toward Learning Local Culture via TCLPB

\begin{tabular}{llllll}
\hline No & Items & SA (\%) & A (\%) & D (\%) & SD (\%) \\
\hline \multirow{2}{*}{16} & TCLPB allowed me understand more local culture. & 16 & 5 & 0 & 0 \\
& I felt tired of finding words to introduce local culture and hence I don't like & $76.20 \%$ & $23.81 \%$ & $0 \%$ & $0 \%$ \\
17 & 1 & 3 & 9 & 8 \\
& TCLPB. & $4.76 \%$ & $14.29 \%$ & $42.86 \%$ & $38.10 \%$ \\
& It was worthwhile taking efforts to find words to describe the local culture in the & 12 & 7 & 1 & 1 \\
& picture books. & $57.14 \%$ & $33.33 \%$ & $4.76 \%$ & $4.76 \%$ \\
& Learning local cultural knowledge through TCLPB was more interesting than & 14 & 4 & 2 & 1 \\
19 & learning in the textbooks. & $66.67 \%$ & $19.05 \%$ & $9.52 \%$ & $4.76 \%$ \\
20 & It was difficult and boring to learn local knowledge through TCLPB. & 3 & 2 & 7 & 9 \\
& & $14.29 \%$ & $14.29 \%$ & $33.33 \%$ & $42.86 \%$ \\
\hline
\end{tabular}

All students agreed that TCLPB allowed them to understand more local culture, and 85.72\% thought that learning local culture through TCLPB was more interesting than learning in the textbooks. The reason for their reaction is probably the themes of the local culture explored in this study is very close to students' real life, and these cultural issues are so unique and representative to their society that they are appealing to the students and obtain their great concern. In addition, there were $90.47 \%$ of students thought it was worthwhile taking efforts to find words describing the local culture and $80.96 \%$ felt comfortable to find words to introduce local culture. Their responses echo Kitao's (1911) finding that through cultural teaching, language learners can master the target language and its culture as well.

In sum, most of students felt confident and interest in creating local culture picture books in English and believed TCLPB could enhance their English ability and increase their vocabulary words. Most of the students felt TCLPB appealing and interesting, especially listening to other groups' reading aloud their picture books at the end of task. Accordingly, students listened to the target words four times since the target works were applied in each group's story books in different genres. This is probably the main reason why students in this study improved their English vocabulary significantly. Furthermore, during TCLPB, students had to struggle exchanging their ideas with different members, which gave them the precious opportunities to practice the social communication skills and further to build up their social relationship. 


\section{Results of Semi-structured Interviews}

The interviews were conducted all the students participating in this study to further understand the reasons why they liked or disliked TCLPB, their preference of writing genres of picture-book creation, and the most impressive or difficult tasks they have experienced. Four semi-structured questions were delivered and students' responses are as follows. In the parenthesis of citations, L represents low English achievers, I intermediate English achievers and $\mathrm{H}$ high English achievers.

Q1. Do you like the activities of TCLPB? Why or why not?

Sixteen out of 21 students showed great interest in participating in the activities of TCLPB because of the following reasons. The task of TCLPB was challenging (L3, L9, L10, L12, L17; I4; H6, I13, H15, H16, H19), and closely related to their daily life (L3, L17, L12, L9; I13; H6, H16, H19). They could cooperate with each other in creating story books (L2, L9, L10, L12, L14, L17, I4, I13; H6, H16, H18, H21), talking freely and actively during co-creation of picture books (L10; I1, I13; H6, H15, H16). Some felt they became getting more and more closed to their teammates while co-creating the picture books (L2, L3, L10, L12, L14; I4, I13; H18), and some enjoyed picture books created by other groups (L2, L8, L9, L10, L12, L14, L17; I4, I13; H6, H16, H18, H19, H21). Above all, most of them found that English vocabulary words became more easily to memorize (L2, L9, L10, L12, L14, L17; I4, I13; H6, H16, H18, H19), and they more cherished their precious natural resources in Penghu (L2, L8, L9, L10, L12, L14; I13, I4; H6, H15, H16, H18, H19), and felt proud of themselves being able to introduce Penghu cultures in English (L2, L10, L12, L14; I4, I13; H6, H16, H18, H19).

However, five students (L5, L8, L20; I11; H7) showed negative opinion on joining TCLBP because they found some of their teammates were not cooperative, arguing with each other or chatting instead of discussing. The only one high English proficiency student felt TCLBP tasks were not appealing to him because he already knew a lot about the culture knowledge. While, the three low English proficiency students felt TCLPB tasks were too difficult for them to complete. Generally speaking, most students were in favor of TCLPB because they had more opportunities to cooperate with their teammates, challenge different tasks, acquire English words spontaneously, discover many precious local resources and be proud of being able to introduce local culture in English.

Q2. How do you evaluate the impacts of TCLPB on improving your own English vocabulary ability?

A majority of students interviewed said that they made great improvement on both vocabulary ability and sentence comprehension. It's because during TCLBP, the target vocabulary was integrated into students' picture books, and further reviewed when students listened to other groups' reports, and students acquired the target words accidentally. Students' responses in interviews are triangulated with their significant performance in the posttest of English vocabulary.

Q3. What are the most impressive task and the most difficulties you were encountered during TCLPB?

Eighteen students interviewed said that the most impressive activity they experienced during TCLPB was the processes of group discussions with their teammates even though four of them were bothered with the conflicts among their teammates during discussions. As to the most challenging things they were encountered, they though it was hard to spell words correctly (L3, L10; I1, I11; H15, H18, H21), to create sentences with the target words to describe the plots they wanted to present (L2, L9, L14; I11, I13;H7, H15, H18, H21), and to cooperate with their teammates well (L5, L8; I4; H16, H19). 
Q4. Do you prefer writing “information books" or "storybooks"?

As to the preferences on the genres of co-creation of picture books, 13 out of 21 students interviewed (L2, L8, L9, L10, L12; I4, I11; H6, H15, H16, L17, H18, H21) preferred information books because information books were more real to their life without brainstorming complex plots or creating make-up characters. The other eight students felt it was more fun to create picture books in the genre of story books because they enjoyed creating the settings, plots, and roles of characters and made the content of their picture books more impressive, vivid and interesting. Furthermore, they usually talked a lot and laughed with each other.

\section{Conclusions and Implications}

\section{Conclusions}

The conclusions, main findings of the study, are fully answering to the three research questions set up for this study: the effects of task-based co-creation of local English picture books on improving English vocabulary ability of Penghu 5th graders with different proficiency levels, on improving their cultural knowledge of Penghu, and their responses to learning activities of creating local English picture books with their classmates.

According to the analysis data above, after the 16-week experimental instruction, all of participants in this study have made a significant improvement on their English vocabulary ability in terms of recognition of English word sounds, word meanings, and word forms and spellings of the target words applied in their culture picture books. Furthermore, all of the students with three different proficiency levels made significant progress in their local knowledge and all responded to TCLPB with very positive attitude, believing that TCLPB enhanced their confidence and interest in learning English, especially in writing English picture books with peers, increased their English vocabulary size, and helped them understand their own culture in depth. In sum, TCLPB enables students with different English proficiency levels to conduct challenging writing tasks, to increase their English vocabulary ability accidentally, to explore their own culture profoundly, and to cooperate with their peers in English writing effectively and with joy.

\section{Pedagogical Implications}

Based on the practical experiences of implementing TCLPB into English instruction, some pedagogical implications are offered for teachers who are interested in adopting the teaching mode of TCLPB to their English classroom teaching.

Use teaching strategies to help students brainstorm relevant words for writing tasks. In the study, around $15 \%$ of students did not fully enjoy TCLPB since they felt frustrated to find appropriate words to express what they wanted to convey, which made the writing task longer and tediously. Thus, in the preparation stage, teachers might adopt such teaching strategy as concept-mapping to lead students to brainstorm relevant words for writing. For example, design a worksheet with the key word "turtle" in the center and then have students name out any words related to the word "turtle" as many as possible. This strategy can bring about positive effects on building up the students' words repertoire, therefore, increasing the writing fluency.

Provide students diverse activities to practice new words before writing. Some students responded that they had hard time to integrate specific-target words into their writing at the initial stage, which jeopardized their fluency of creating picture books. Therefore, it is suggested to design diverse activities for students to be familiar with those target words by practicing them in different contexts before those target words are integrated into their writing. For example, have students fill target words into incomplete sentences, 
make sentences with these target words, or read short articles contextualized with those words. Consequently, students could practice those target words in different contexts and thus understand the lexical usage of those words, then triggering their repertoire of these target words to co-write sentences for their picture books.

Encourage less-confident students to take more responsibility for the creation tasks. Because of different personalities and English proficiency levels, some students talked actively while some kept silent all the time in the group discussions. It is crucial to encourage students with less-confidence to participate in the learning activities more actively. One of the effective ways is to have those students take more responsibility in the creation of picture books, such as searching for relevant materials online for group discussions, designing routs for data searching in site, or serving the role of writers or drawers in their group.

\section{Limitations and Suggestions for Future Studies}

In spite of the significant effects found, there are still several limitations that the study was confronted. First, the sample size of research subjects was small and restricted to 5 graders. In fact, studies with the same design, which are implemented to different graders or in different school districts might result in different research results. Therefore, more students in different grades could be included in the future investigation. Besides, because of the limited number of students in the Penghu County, the study was conducted in a single-group experimental design. Concerning the reliability and validity of studies, a quasi-experimental design with both the experimental group and the control group will be much more appropriate and convincing for the future studies.

Lastly, it is highly recommended that future studies could turn students' creative local picture books into electronic books or sound files, serving as one of the local learning resources and sharing with teachers and students in Penghu as well as with those all over Taiwan and worldwide.

\section{References}

Andrew, M. B. (2009). Deepened mirrors of cultural learning: Expressing identity through e-learning. CALICO, 26(2), 1-12.

Barcroft, J. (2007). Effects of word and fragment writing during L2 vocabulary learning. Foreign Language Annals, 40(4), 713-725.

Byram, M. (1997). Teaching and assessing intercultural communicative competence. Philadelphia: Multilingual Matters.

Carolyn, K. (1992). Cooperative language learning: A teacher's resource. Englewood Cliffs, N.J.: Prentice Hall Regents.

Chen, C. S. (2011). The effects of picture books on cultural knowledge and English learning attitude of elementary school students (Unpublished master thesis, National Taipei University of Education, Taiwan).

Chen, C. Y. (2011). The effects of task-based language teaching on first graders' English speaking proficiency in an elementary school in New Taipei City (Unpublished master thesis, National Taipei University of Education, Taiwan).

Du, A. S. (2013). A study of teaching multiculturalism with English picture books in EFL elementary school (Unpublished master thesis, National Taiwan University Science and Technology, Taiwan).

Duke, N. K., \& Purcell-Gates, V. (2003). Genres at home and at school: Bridging the known to the new. Reading Teacher, 57(1), 30-37.

Flower, L., \& Hayes, J. R. (1981). A cognitive process theory of writing. In R. B. Ruddell, M. R. Ruddell, and H. Singer (Eds.), Theoretical models and processes of Reading (pp. 928-950). Newark, DE: International Reading Association.

Gaston, J. (1992). Cultural awareness teaching techniques. Brattleboro, Vermont: Pro Lingua Associates.

Ghoson, I. (2002). Four good reasons to use literature in primary school. EFL Journal, 7, 172-179.

Harp, B., \& Brewer, J. (2005). The informed reading teacher: Research-based practice. Upper Saddle River, NJ: Merrill Prentice Hall.

Hsieh, S. W. (2013). The effectiveness of task-based instruction on 8th graders' English learning achievement and English learning attitude (Unpublished master thesis, National Taipei University of Education, Taiwan).

Inan, H. Z. (2010). Examining language of information books for children. Education, 130(3), 399-403. 
Karabinar, S. (2012). The attitudes of EFL teachers towards teaching culture and their classroom practices. Journal of Educational and Social Research, 2, 113-126.

Kim, H. S. (2008). Culture and the cognitive and neuroendocrine responses to speech. Journal of Personality and Social Psychology, 94, 32-47

Kitao, K. (1991). Teaching culture in foreign language instruction in the United States (ERIC Document Reproduction Service No. ED330214).

Laufer, B. (1998). The development of passive and active vocabulary: Same or different? Applied Linguistics, 19, 255-271.

Lynch, B. C., Carl, M. T., \& Kathy, G. S. (2011). Learning about children and their literature. Essentials of children's literature (7th ed.). Pearson: Pearson Higher Ed.

Long, M., \& Norris, J. (2000). Task-based teaching and assessment. In M. Bryan (Ed.), Encyclopedia of language teaching (pp. 597-603). London: Routledge.

Lynch-Brown, C., \& Tomlinson, C. (2005). Essentials of children's literature (5th ed.). San Diego, California: Pearson Education.

Mahurt, S. F. (2005). The aesthetics of Caribbean children's literature. Boston: Pearson Education.

Manifold. M. C. (2000). Picture books as a social studies resource in the elementary school classroom. Bloomington, IN: ERIC Clearinghouse for Social Studies/Social Science Education.

Marlowe, B. A., \& Page, M. L. (2005). Creating and sustaining the constructivist classroom (2nd ed.). Thousand Oaks, CA: Corwin Press.

Martin, E. (2009). Bipolar expeditions: Mania and depression in American culture. Princeton: Princeton University Press.

McCafferty, S. G., Jacobs, G. M., \& Iddings, A. C. D. (2006). Cooperative learning and second language teaching. Cambridge: Cambridge University Press.

Meek, M. (1996). Information and book learning. Stroud, Glos: Thimble Press.

Ministry of Education. (2008). Nine-year integrated curriculum guidelines for the English course. Retrieved 2012, July 1 from http://www.edu.gov.on.ca/eng/curriculum/secondary/english910currb.pdf

Moran, P. R. (2001). Teaching culture: Perspectives in practice. Boston: Heinle \& Heinle.

$\mathrm{Ni}, \mathrm{P} . \mathrm{H}$. (2014). The effects of integrating community teaching materials into task-based language teaching on word recognition and local (Unpublished Master thesis, National Taipei University of Education, Taiwan).

Ovando, C., Combs, M. C., \& Collier, V. P. (2006). Bilingual \& ESL classrooms. In Teaching in multicultural contexts (4th ed.). NY: McGraw Hill.

Perfetti, C. (1985). Reading ability. New York: Oxford University Press.

Saunders, P. L., \& Chester, A. (2008). Shyness and the Internet: Social problem or panacea? Computers in human behavior, 24, 2649-2658.

Slamecka, N. J., \& Graf, P. (1978). The generation effect: Delineation of a phenomenon. Journal of Experimental Psychology: Human Learning \& Memory, 4, 592-604.

Slattery, M., \& Willis, J. (2001). English for primary teachers: A handbook of activities and classroom language. Oxford: Oxford University Press.

Swales, J. (1988). Discourse communities, genres and English as an international language. World Englishes, 7(2), 211-220.

Tang, Y. C. (2012). English vocabulary ability and learning attitude of sixth graders in a task-based language teaching remedial program (Unpublished master thesis, National Taipei University of Education, Taiwan).

Tsai, S. T. (2013). The effects of co-writing picture books on sixth graders' word recognition, sentence making abilities and English learning (Unpublished master’s thesis, National Taipei University of Education, Taiwan).

Tu, L. M. (2012). The effect of task-based instruction on English word recognition and spelling abilities of elementary third graders (Unpublished master's thesis, National Taipei University of Education, Taiwan).

Vygotsky, L. S. (1978). Mind in society: The development of higher psychological processes. Cambridge, MA: Harvard University.

Wertsch, J. (1991). Voices of the mind: A sociocultural approach to mediated action. London: Harvester Press.

Willis, J. (1996b). A framework for task-based learning. London: Longman.

Yopp, R. H., \& Yopp, H. K. (2000). Sharing informational text with young children. Reading Teacher, 53, 410-423. 


\section{Appendix A}

\section{Information Book}

Stone Weirs

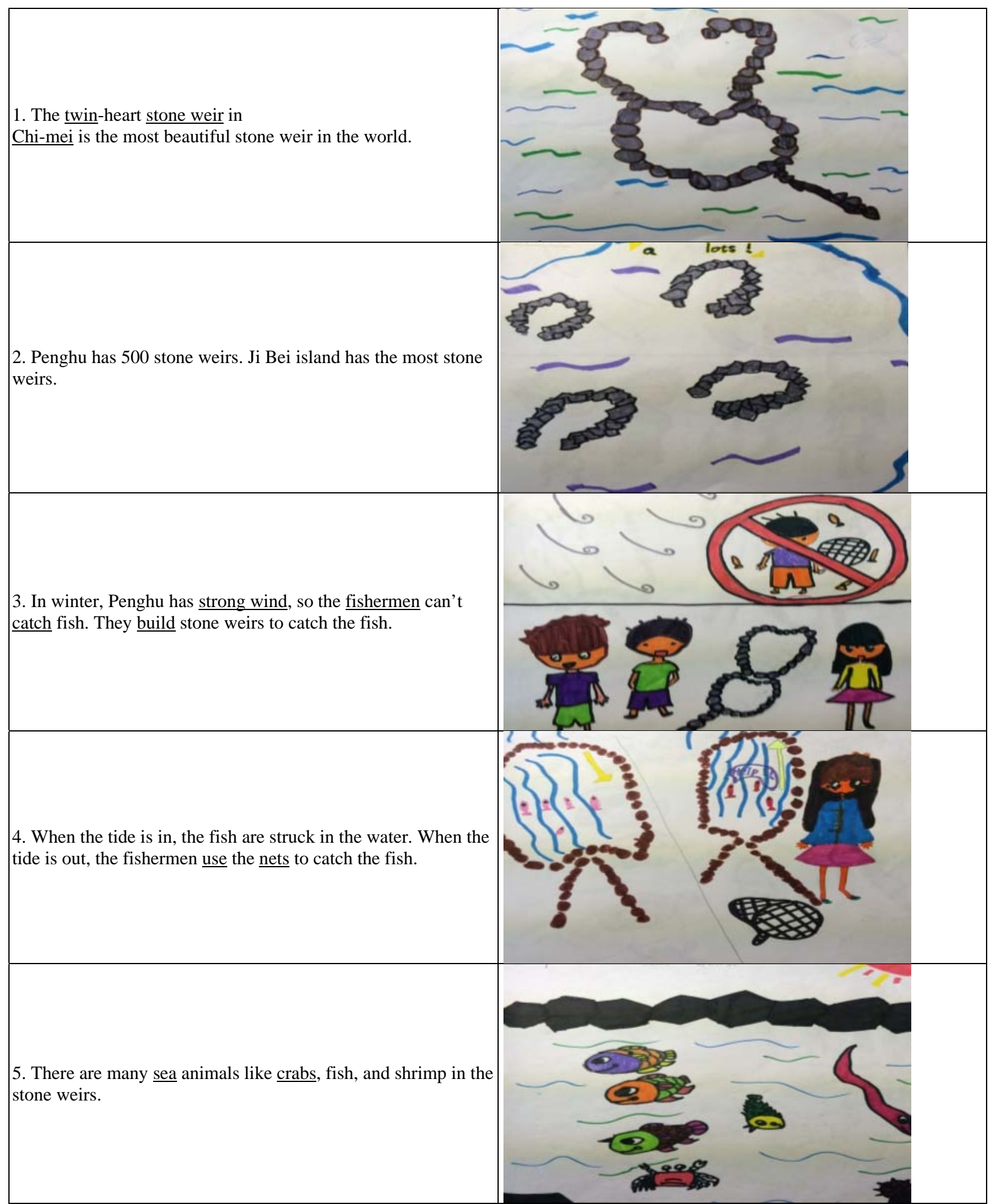




\section{Appendix B}

\section{Storybook}

Stone Weirs

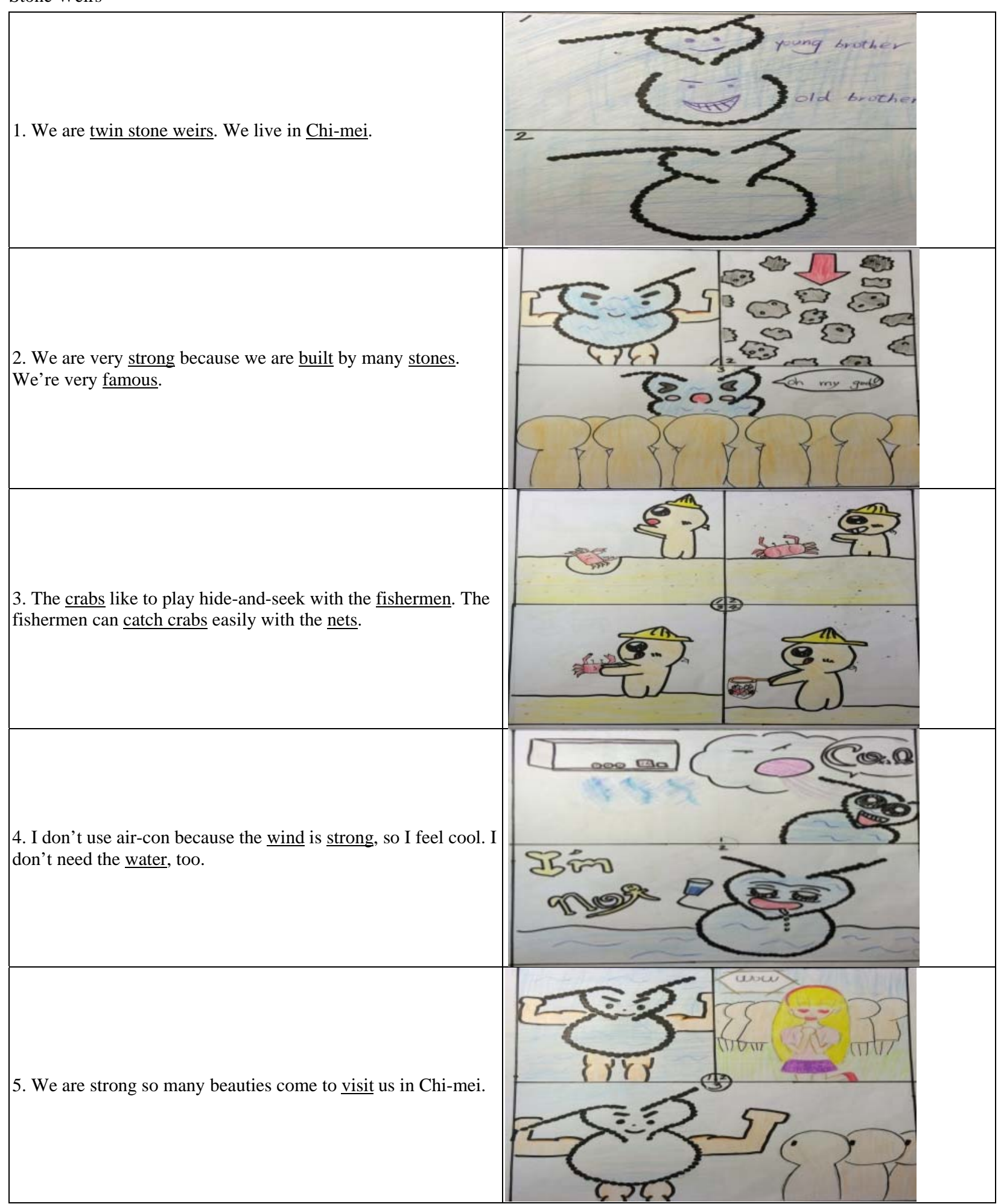

